ARCHIVO ESPAÑOL DE ARTE, LXXXVI, 342

ABRIL-JUNIO 2013, pp. 107-122

ISSN: 0004-0428

\title{
JUAN GÓMEZ DE MORA, ANTONIO MANCELLI Y CASSIANO DAL POZZO
}

\author{
José MANuel Barbeito \\ Universidad Politécnica de Madrid
}

\begin{abstract}
Cuando en 1626 vino a Madrid el cardenal legado Barberini, una de las estancias de su aposento en las Casas del Tesoro se decoró con un conjunto de mapas y planos. Gracias a nueva documentación del Archivo de Palacio poseemos una descripción de estas obras y sabemos que se compraron a Antonio Mancelli por intermedio de Gómez de Mora. Dado que entre los miembros de la legación se encontraba Cassiano dal Pozzo, apasionado coleccionista de dibujos y grabados, el artículo analiza la relación entre estos tres personajes. Y lo hace sobre el escenario de una ciudad, Madrid, que deberá precisamente a Mancelli su primera planimetría urbana.
\end{abstract}

Palabras clave: Casa del Tesoro; Cassiano dal Pozzo; Cardenal Francesco Barberini; Juan Gómez de Mora; Antonio Mancelli; Plano de Madrid; Vista de la Plaza Mayor.

\section{JUAN GÓMEZ DE MORA, ANTONIO MANCELLI AND CASSIANO DAL POZZO}

When in 1626 Cardinal Barberini arrived in Madrid, one of the rooms in his chambers in the Casas del Tesoro was decorated with a group of maps and plans. Thanks to new documentation in the Royal Palace Archive, we have a description of these works and know that they were purchased from Antonio Mancelli through the intervention of Gómez de Mora. Given that Cassiano dal Pozzo, a passionate collector of drawings and prints was one of the members of the Cardinal's legation, the author analyses the relationship among these three personages, with the city of Madrid as the stage, and for which precisely Mancelli created the first urban planimetry.

Key words: Casa del Tesoro; Cassiano dal Pozzo; Cardinal Francesco Barberini; Juan Gómez de Mora; Antonio Mancelli; plan of Madrid; View of the Plaza Mayor.

1626. El 24 de mayo Francesco Barberini, hermano del pontífice y cardenal legado hace su entrada pública en Madrid. El rey ha salido a recibirle hasta la puerta de Alcalá y tras recorrer juntos las calles de la ciudad le deja a la entrada de la iglesia de Santa María, donde tiene lugar un breve oficio religioso. Después, el cardenal y sus acompañantes continúan hasta el alojamiento que se les ha dispuesto junto al alcázar de la Villa.

De todo da pormenorizada cuenta Cassiano dal Pozzo en un diario donde recoge las vicisitudes del viaje. Miembro de la Academia dei Lincei, amigo de intelectuales y artistas, mecenas y coleccionista, lleva ya tres años al servicio de Barberini cuando, formando parte del séquito del cardenal, 
llega a Madrid ${ }^{1}$. El hecho de que Cassiano considere el edificio donde se les ha preparado su alojamiento, la Casa del Tesoro, como un palacio, revela como las antiguas casas principales de don Bernardino de Mendoza conservaban todavía una cierta prestancia que las hacía destacar entre las abigarradas piezas de servicio que flanqueaban el alcázar. Adquiridas por Felipe II, durante su reinado fueron ocupadas por distintos oficiales empleados al servicio del soberano entre los que la documentación ha ido rescatando el nombre de algún ilustre artista. Junto a ellos encontraron allí acomodo otros personajes de los que poblaban la corte, por ejemplo el guardajoyas Antonio Boto o el secretario Alonso Muriel, los últimos huéspedes de que tenemos noticia, antes de que la marcha de Felipe III a Valladolid dejara en desuso el edificio².

Pero su padre ya había vaticinado que no habría mejor medio de conservar la corte en Madrid que mudándola, y el 18 de febrero de 1606, parece que con un suspiro de alivio por parte de la mayoría de oficiales y criados, se publicaba el regreso a la ciudad del monarca ${ }^{3}$. Poco después la Casa del Tesoro se convierte en protagonista de una sorprendente noticia. El 23 de diciembre escribe Cabrera de Córdoba: "Vinieron Sus Magestades del Pardo a los 5 deste para tener aquí la Pasqua y fueron huéspedes del Duque de Lerma los dos días primeros que llegaron, el cual los aposentó en las piezas que tiene en la Casa del Tesoro, que estuvieron muy ricamente aderezadas, y los reyes en diferentes aposentos, y fueron servidos con mucho regalo, y la primera noche tuvieron comedia, y el segundo día a la tarde otra". La comedia fue seguida de un torneo que resultó un fiasco, por lo que se decidió repetirlo unos días después, el 20 de enero de 1607: "El torneo que se publicó cuando se hizo el otro, habrá mes y medio, en el patio de las Casas del Tesoro donde tuvo el Duque de Lerma hospedados dos días a los reyes, se hizo ayer en el patio de palacio ... y a la noche hubo sarao donde se dieron los premios". Y no sólo eso, sino que también, "háse hecho en el segundo patio de las Casas del Tesoro un Teatro donde vean Sus Magestades las comedias como se representan al pueblo en los corrales questan deputados para ello, porque puedan gozar mejor dellas que cuando se les representa en su sala, y así han hecho alrededor galerías y ventanas donde esté la gente de palacio, y Sus Magestades irán allí de su cámara por el pasadizo questa hecho, y las verán por unas celosías"

Cabrera está bien informado de lo que sucede en la corte, y al repetir en dos días consecutivos la noticia no hay por qué dudar de lo que dice, pero la documentación de obras no ha revelado hasta ahora ninguna referencia de estas actividades. De todas formas durante los próximos años los reyes no iban a pasar demasiado tiempo en su alcázar madrileño, buena culpa de lo cual puede atribuirse al inicio de grandes obras que van a trastocar por completo la vida en palacio ${ }^{5}$. La Villa había ofrecido al monarca, en pago por el regreso de la corte, costear un nuevo cuarto para la reina, obras que se comenzaron en 1608 y no tardaron en convertirse en una reforma completa de la fachada del edificio implicando también el frente de los aposentos del rey. Así que cuando en 1610 llega a la ciudad el

\footnotetext{
${ }^{1}$ Anselmi, A, 2004. La entrada quedó recogida en diversas relaciones contemporáneas, como la de Francisco Gómez de León o la de Juan de la Rea. Véase Simón Díaz, J. (ed.), 1982: 337-342.

${ }^{2}$ Un informe del 5 de mayo de 1601 sobre las reparaciones urgentes a realizar en el alcázar y los otros edificios de la corona repartidos por la ciudad, cita "Las cassas del Thesoro en donde bive el secretario Muriel y Antonio Boto es menester acabar de tejar el paso que se hizo para passar al quarto de la galeria y la escalera del patio y hacer unos cerramientos para que no entren en los tejados; en el quarto prinçipal se an caido dos chimeneas y an echo mucho daño en los tejados". Archivo General de Palacio (AGP). Sección Administrativa (SA). Leg. 710.

${ }^{3}$ Porreño, B, 1639: 147.

${ }^{4}$ CABrera de Córdoba, L., 1857: 295-297.

${ }^{5}$ Gerard, V., 1978: 237-257. En noviembre de 1609, poco después de comenzadas las obras, se rumoreaba en la corte que los reyes, que terminaban su jornada en El Escorial, "trataban de irse a Alcalá de Henares en lugar de venir aquí, por dar lugar a la obra de palacio y librarse del polvo de los materiales", resolución que finalmente no se tomó. Con todo, durante los próximos años los monarcas prodigaron los viajes y estancias fuera del alcázar. CABRERA DE CóRDOBA, L., 1857: 334 .
} 


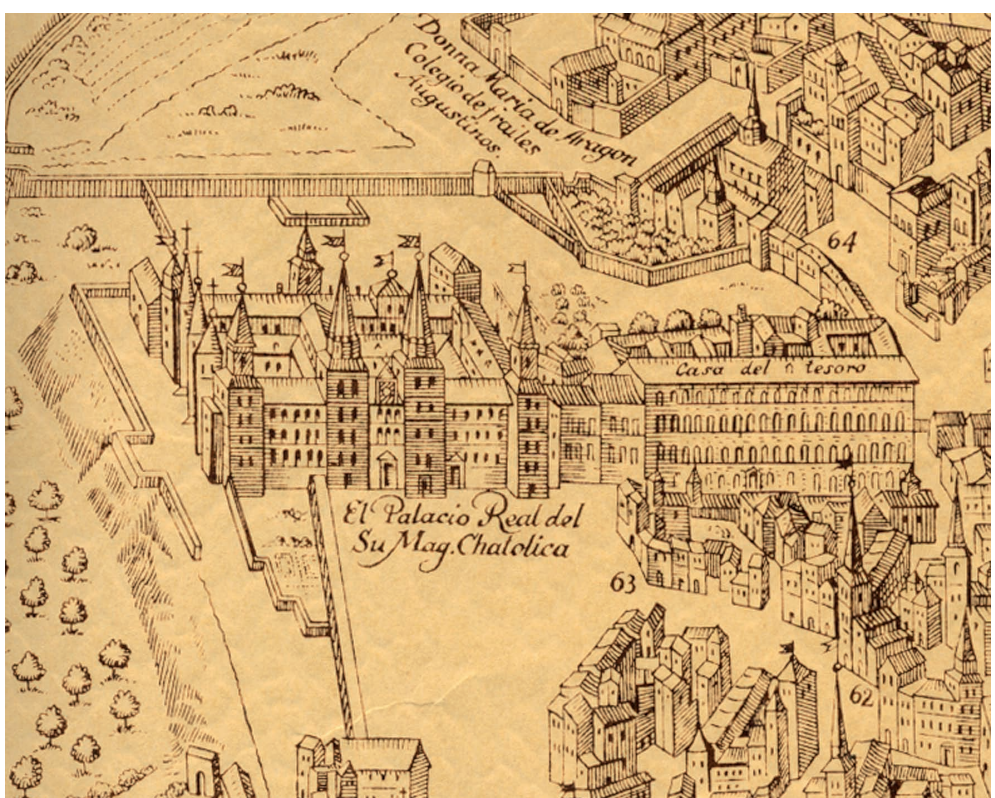

Fig. 1. Fragmento del plano La Villa de Madrid corte de los Reyes Catolicos de Espanna.
Príncipe Filiberto de Saboya, sobrino del monarca y gran Prior de San Juan, encuentra el alcázar convertido en un caos de talleres, grúas y andamios entre los que pululan centenares de obreros. Filiberto conocía bien ese palacio en el que había residido en 1606, durante su primer viaje a España, cuando fue aposentado junto a su hermano Vittorio Amedeo en las dependencias de la entreplanta del ala más occidental del edificio, la que miraba hacia el Manzanares, justo debajo del Cuarto del Rey. Pero en esta su segunda visita a la corte, el príncipe es alojado fuera del alcázar.

"Habiase dicho que le aposentarían en palacio, en el cuarto donde estuvo con su hermano la otra vez, y agora le han señalado el de la Casa del Tesoro, que son muy buenas piezas, cerca de palacio, para donde había pasadizo; y agora dicen que le han cerrado y habrá de salir a la calle para pasar a palacio; y en otras cosas se echa de ver que no le admiten con la demostración que se había dicho, que debe ser por el descontento que se tiene de su padre"

Esta vez sí que unos cuantos registros dan cuenta de los trabajos realizados para acomodarle, entre ellos la construcción de la escalera que bajaba a la Priora: "desde un corredor que cae a la guerta de la Priora sobre un cubo ochavado hicimos una escalera de madera de mas de 44 pies de largo ... escalera de madera que de nuebo se hizo en la Casa del Tesoro para servicio del gran Prior", seguramente la escalera por la que después tantas veces bajaría el cardenal Barberini para entrevistarse con el Conde-Duque en los jardines ${ }^{7}$ (fig. 1).

\footnotetext{
${ }^{6}$ Cabrera de Córdoba, L., 1857: 420. Para las fechas y circunstancias de sus sucesivos viajes a España, hemos usado la información de Gascón de Torquemada, que estuvo adscrito a su servicio. GASCÓn DE ToRquemadA, J., 1991. Véase también lo que deja escrito el noble polaco Jacobo Sobieski, acerca de los muchos comentarios que se hacían sobre la permanencia del joven príncipe en la corte: "Unos decían que su tío le quería mucho, y tenía proyectos de darle el virreinato de Portugal ... o el Almirantazgo de la Armada española, que pertenece también al orden de los superiores puestos en España. Otros pretendían que el rey le guardaba de rehén y garantía por parte de su cuñado, Duque de Saboya, cuya inconstancia de ánimo conocía. Sea lo que quiera, en mucha consideración se tenía a este joven príncipe; pero es preciso confesar también que el cortejo de españoles que se le dio, so pretexto de honrarle mas, le rodeaba y vigilaba en todas partes, como si fuera un prisionero". En García Mercadal, J., reed. 1999, vol. III: 185.

${ }^{7}$ El 27 de octubre de 1610 se libraban 500 ducados al pagador Bartolomé de Arce "para arreglar la Cassa del Tesoro donde ha de posar el ilmo. ppe. Filiberto". Responsable de buena parte de estos trabajos, fue Pedro Rodríguez Majano, uno de los contratistas de las obras de la nueva fachada del alcázar. Entre las libranzas hay una nota de interés, un pago "por los rreparos de la casa rreal del Thesoro y ofiçios que se azen en la Casa de las Matematicas para serbicio del Gran
} 
Filiberto de Saboya residió en Madrid hasta el primero de noviembre de 1612, cuando no sabemos si honrado o despechado, marchó rumbo a Sevilla con el cargo de Generalísimo de la Mar. Pero la Casa del Tesoro no iba a quedar desocupada mucho tiempo, porque un par de días después de la salida del príncipe se despachaba una cédula real autorizando la instalación en el edificio de las monjas de la Encarnación entretanto que se acababan las obras de su nuevo convento. Las monjas -cinco religiosas y dos más que profesaron después-, permanecieron allí alojadas hasta el 2 de julio de 1616, cuando en una solemne procesión y acompañadas por toda la corte, se trasladaron al vecino monasterio ${ }^{8}$.

Un año después, en agosto de 1617, Filiberto de Saboya reaparecía en la corte, presentándose en El Escorial donde estaban el rey y sus hijos. Junto a ellos marchó en septiembre a Lerma, para la inauguración de la nueva Colegiata levantada por el privado, regresando después con la familia real a Madrid. De nuevo un conjunto de partidas detallan los trabajos realizados en la Casa del Tesoro para aposentarle: obras en la escalera que bajaba a la huerta de la Priora, atajos, encerados, celosías, marcos para las vidrieras. Parece que esta vez sí se le dejó al príncipe utilizar el pasadizo hasta el alcázar, pues uno de los pagos se refiere a la construcción de "un pedaço de corredor çerrado con una bentana para pasar al pasadiço para yr a palacio ... con tres suelos de maderos de a ocho entablados el uno labrado y los dos toscos ... en el patio de adentro de la Casa del Tesoro". Pero en general se trata de pequeñas cosas que no significan ninguna transformación sustantiva de los espacios ${ }^{9}$. El príncipe saboyano volvió pues a instalarse en la que ya parecía su casa y allí residió los próximos dos años, hasta que en 1619, días después de que la familia real hubiera partido sin él hacia Portugal, pusiera de nuevo rumbo a Italia.

$\mathrm{Al}$ regreso de Lisboa Felipe III cayó enfermo y aunque pareció reponerse, nunca recuperó del todo la salud. Falleció en 1621 subiendo al trono el joven Felipe IV, y junto a él nuevos ministros y privados, cambios que en lo público afectaban al gobierno de la monarquía y en lo doméstico a la multitud de oficiales que componían la servidumbre de palacio. Las obras del alcázar se ralentizaron. De todas formas estaban ya muy avanzadas, prácticamente solo pendientes de los remates de las torres, y la fachada lucía magnífica. Un entendido como Cassiano no dudará en afirmar che visto in faccia fa bellissima vista è d'architettura all 'italiana all'usanza con finestre grandi adornate de' suoi frontispitii ${ }^{10}$. También el soberbio aspecto del palacio había llamado la atención tres años antes a los visitantes ingleses que acompañaron al heredero de la corona inglesa Carlos Estuardo, cuando en 1623 llegó a Madrid. Una visita que cogió desprevenida a la corte, obligada a improvisar primero una recepción pública como la que el Príncipe de Gales merecía y después un alojamiento adecuado para la calidad de semejante huésped, cosa que en esta ocasión se resolvió dentro del propio alcázar. A Carlos Estuardo se le asignaron las habitaciones que había dejado desocupadas don Baltasar de Zúñiga, fallecido unos meses antes: un aposento situado en la entreplanta, que daba hacia la huerta de la Priora, justo bajo las habitaciones de la reina ${ }^{11}$.

Prior de San Juan”. Poco después Gómez de Mora pediría una compensación por las molestias causadas, pues era en su casa de aposento donde se leían las matemáticas. AGP. Caja 9.385, expte. 15. Para la petición de GómEZ DE MorA, véase Tovar, V., 1986: 23.

${ }^{8}$ Para la Cédula Real del 3 de noviembre de 1612, AGP. CR. T. XI, fols. $273 v^{\circ}, 274$. Hay sin embargo un cierto baile de fechas, porque todos los cronistas de la Villa, tanto Quintana, como León Pinelo o el maestro Gil González Dávila, adelantan el traslado al 3 de febrero, lo que significaría que durante un tiempo las monjas compartieron aposento con el Gran Prior. Asimismo, una nómina al carpintero Gabriel Benito, de los trabajos realizados "para acomodar las monxas recoletas agustinas que se truxeron de Santa Ysabel”, está fechada el día 8 de febrero. AGP. Caja 9390 expte. 5.

${ }^{9}$ El 13 de diciembre de 1617 Juan Gómez de Mora firma y autoriza la tasación hecha por el aparejador Juan de Herrera de todos estos trabajos. AGP. Caja 9.388 expte. 9.

${ }^{10}$ Apunta Cassiano como non è finito, e continuamente si lavora. Anselmi, A., 2004: 105.

${ }^{11}$ Para la ocupación de las diferentes estancias del alcázar en estos primeros años del reinado de Felipe IV, BARBEITO, J.M., 2010. 
No han aparecido registros en las obras que indiquen que la Casa del Tesoro se utilizara entonces para albergar parte del séquito o de la servidumbre que acompañaba al heredero, aunque es posible que así fuera. En cualquier caso sus dependencias seguían dando cabida a personal de palacio, como el maestro de la Capilla Real, Mateo Romero, el Maestro Capitán, cuyas habitaciones estaban en el patio segundo, debajo de los cuartos en que se alojaría después el Patriarca Pamphili. Con la llegada en 1626 del cardenal Barberini, fue preciso remover a varios de estos oficiales, entre ellos don Pedro de Landazuli, guardarropa del Conde-Duque, al que se le quitaron los aposentos bajos, que tenían sus ventanas a la calle ${ }^{12}$. Es una pena que los planos que nos han llegado del edificio sean tan poco explícitos. Ni los diferentes croquis, ni los planos parciales en los que se dibujan partes de la casa, ni el general de Ardemans de la Biblioteca Nacional de París, son suficientes para recomponer unas plantas que nos permitan recorrer con cierta seguridad las dependencias. De manera que a pesar de la pormenorizada descripción que nos deja Cassiano dal Pozzo las estancias ocupadas por el cardenal y su séquito siguen constituyendo un laberinto difícil de desentrañar ${ }^{13}$ (fig. 2).

Cassiano cuenta como después de acceder por un callejón, se dejaba la carroza en un pequeño patio desde el que una escalera llevaba hasta la planta alta donde estaban las habitaciones principales. La escalera desembocaba en una sala sin muebles. Ni sillas, ni escabeles, ni mesas. Una especie de vestíbulo donde aguardaban los pajes del cardenal. Luego empezaban las estancias propiamente dichas. En la primera de ellas, ya lujosamente decorada con tapicerías, se había instalado un baldaquino, para las audiencias del prelado. Tenía un balcón que daba hacia "un jardín de Su Magestad", lo que nos sitúa en la crujía trasera del edificio, la que abría sus luces hacia la huerta de la Priora. Seguían otras dos piezas, la primera de ellas decorada con unos paños de las Cuatro Estaciones y la segunda con la historia del Diluvio y el Arca de Noé, tapicerías prolijamente descritas por el autor, que se maravilla de su riqueza. En esta última pieza, más retirada, se había instalado un segundo baldaquino, y la estancia se iluminaba a través de una loggia, o mirador de madera, cerrado con vidrieras y volado sobre los jardines. Siguiendo el recorrido, a mano derecha, se accedía a la cámara o dormitorio del cardenal, decorada con 8 tapices, siete de una serie sobre los Planetas, a los que se había añadido otro donde se representaba a Neptuno. Cassiano habla en este caso de dos ventanas y completa la decoración con una gran profumiera d'argento -seguramente un brasero-, unas sillas de brocado, un arcón y sobre él, la única pintura hasta entonces citada, una Asunción de Anibale Caraccio.

Llegado a este punto Cassiano vuelve atrás, a la estancia anterior al dormitorio, desde la que nos hace bajar por una escalera de pocos escalones hasta una serie de camerinos que completaban

\footnotetext{
${ }^{12}$ Una relación sin fecha, pero que es posterior a 1638, cuando se alojó en las Casas del Tesoro la Princesa de Cariñano, describe pormenorizadamente las piezas y sus ocupantes, desde la época en que sirvieron para el hospedaje del Cardenal legado. Los pasajes citados dicen textualmente: "En este mismo patio ay unos aposentos bajos que tienen bentanas a la calle que los tubo Don Pedro de Landaçuli siendo guardaropa del Conde Duque; quitaronsele para el ospedaje del Cardenal Legado y,... En el quarto que sirbio al Patriarcha Panfilio y fue de los principitos yjos de la Cariñana... debajo destos aposentos esta el quarto que tubo el maestro Capitán questa desocupado y suelese acomodar en el diferentes personas del ospedaje”. AGP. SA. Leg. 710. El maestro Capitán había sido alojado allí dos años antes de que llegara el legado, en 1624, según la Data del pagador Mateo López Bravo del 20 de septiembre. Diversos pagos de las obras realizadas para aderezar sus aposentos en AGP. SA. Leg. 5.208.

${ }^{13}$ Un croquis en el Archivo del Instituto de Valencia de don Juan recoge, todavía en el reinado de Felipe II, las plantas alta y baja con las dependencias del Consejo de Hacienda. Otro en el Archivo del Palacio Real, cosido a un expediente de 1684, refleja todo el conjunto de construcciones en el esquinazo entre las calles del Tesoro y la que llevaba a la Encarnación. Se dibuja el Consejo de Indias, la Botica del Rey y, pasado el callejón de entrada a la Casa del Tesoro y Contaduría de Cuentas, la tahona y panadería ya en la esquina donde doblaba el edificio. Más tardíamente este esquinazo volverá a ser cuidadosamente dibujado, cuando demolida la tahona se instale allí la Biblioteca Pública de Felipe V; y partes de la casa del Tesoro se detallan en el plano del aposento de Juan Bautista Legendre realizado por Saqueti en 1750. Para un riguroso esfuerzo de poner orden en toda esta documentación, véase MARTínEz DíAz, A., 2008: 102-116.
} 


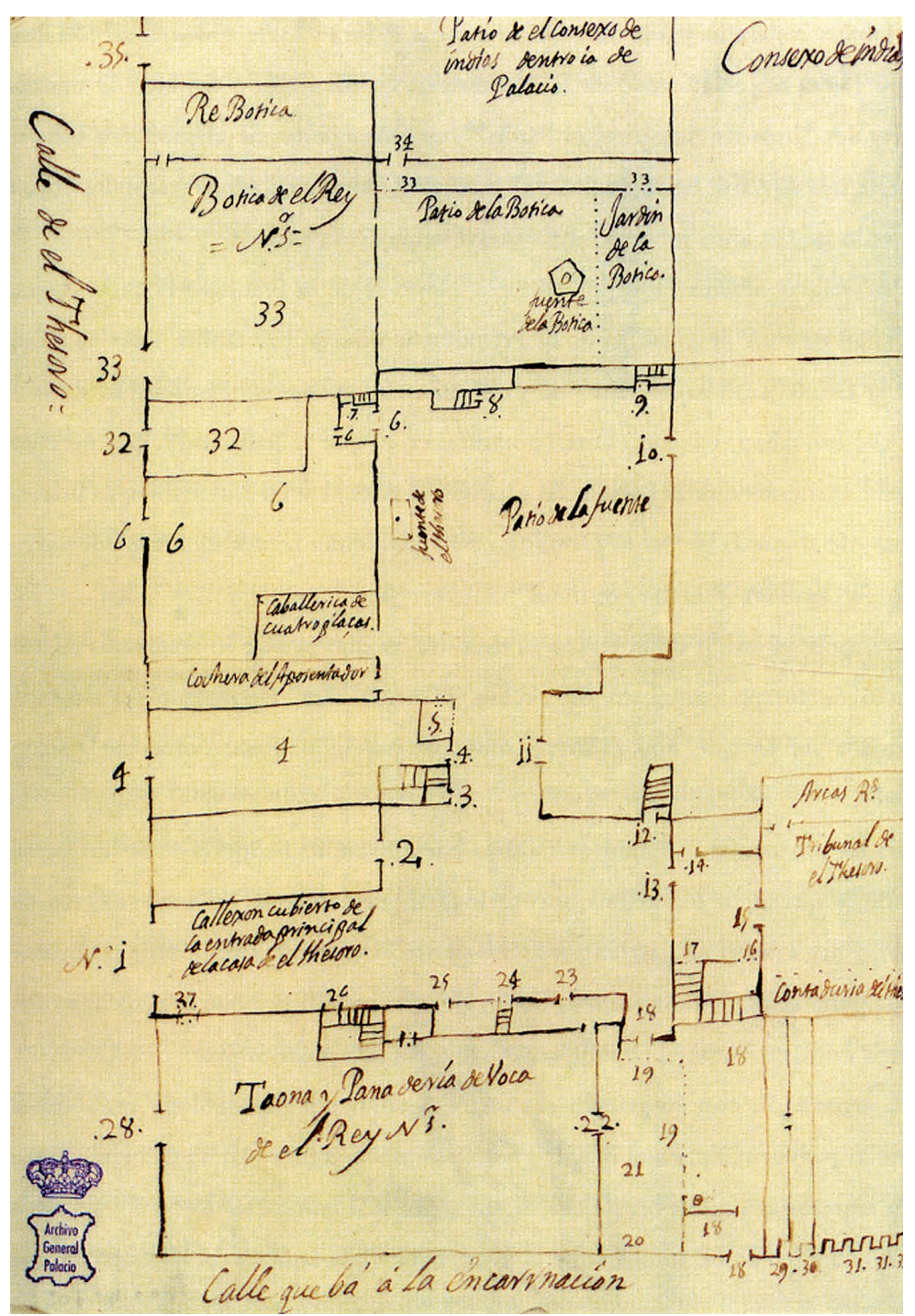

Fig. 2. García de Villagrán, Croquis de la Casa del Tesoro. AGP. SA. Leg. 741.

el cuarto del Cardenal. La primera de esas habitaciones estaba decorada con unas tapicerías de oro y seda en las que se trataba la historia de Cupido y Psique sobre cartones de Rafael. En la segunda una nueva serie de tapices de oro y seda representaban algunos caprichos o "disparates" de Brueghel y finalmente se encontraban, una pequeña capilla donde se oía misa, decorada con tapices de la Historia Sagrada, un pasadizo con mapas de cosmografía en miniatura (un andito con carte de cosmografía miniati) y por último una galería o pequeño corredor con los retratos de los príncipes modernos y del rey ${ }^{14}$.

\footnotetext{
${ }^{14}$ Anselmi, A., 2004: 100-106 para la traducción española y 89-93 para la versión italiana.
} 
Otros autores se hacen eco y confirman lo descrito por Cassiano. Juan Antonio de la Peña publicó ese mismo año 1626 un Discurso de la jornada que hizo a los Reynos de España el Illustrissimo y Reverendissimo. señor don Francisco Barberino donde después de recordar que el aposento del legado era "en el mismo quarto que vivio el señor Principe Filiberto", repasa las distintas estancias y los ricos tapices con que se habían adornado, y recuerda como el guardamangier, panetería, cava y dos cocinas con otros oficios de boca -apropiados para el servicio de un rey-, se habían instalado en las dependencias bajas del patio, seguramente el segundo patio, más retirado. "Enlucieronse de nuevo todas las quadras, assí paredes como maderas, blanquearonse y empedraronse los dos patios; las puertas se hizieron de nuevo con sus cadenas de respeto, y sobre cada una se pusieron las armas del Sumo Pontífice" ${ }^{\text {"15 }}$. De estos reparos quedan algunos registros en la documentación de las obras, como la nota firmada por Gómez de Mora sobre las vidrieras que se instalaron en las habitaciones del cardenal, donde se vuelven a recorrer una a una las estancias de su aposento:

Sala primera: la bentana del mediodia entera; seis cuaterones ciegos de las tres bentanas Antecamara: dos bentanas enteras con cristalinas a la bista

Camara: una bentana entera con cristales a la bista

Pieça de dormir: dos bentanas enteras con tres cristales a la bista

Pieça de comer: una bentana al mediodia con sus cristales

Corredor que cae a la Priora: cinco bentanas con cristalina a la bista; debajo destas bentanas en los balaustres, bidrios ordinarios

Apossento retirado: una bentana de cristales que mira a la Priora ${ }^{16}$.

Adviértase el tono, un punto protocolario, con el que Gómez de Mora describe las piezas, que nos trae inmediatamente el recuerdo de su Relaçion de las Cassas que tiene el rey de España, el cuaderno manuscrito con las trazas de los palacios y la explicación del destino de sus diferentes habitaciones que el maestro mayor realizó en 1626, durante la visita de la legación y que acabó entre los papeles Barberini en la Biblioteca Apostólica Vaticana ${ }^{17}$. Gómez de Mora en su doble condición de aposentador y maestro mayor de las obras reales desplegó una extraordinaria actividad durante esta visita. Su papel lo resume Cassiano en un apunte del día 10 de junio, cuando la condesa de Olivares ofreció una comida a Barberini que acudió "en muceta y ferreruelo, siguiendo el consejo de Juan Gómez de Mora, diputado en el palacio del Tesoro para asistir siempre en las mismas cámaras del señor cardenal como práctico, y que tenía llaves que abrían por todas partes". Gómez de Mora trae y lleva regalos, desde una panera de plata que ese mismo día envía la condesa, hasta las cuatro jacas enjaezadas con el que le obsequiará el 15 de julio Olivares. Anuncia a Cassiano cuando este ofrece al rey los presentes del cardenal: "vino conmigo el señor Juan Gomez de Mora, que atendía como se ha dicho antes, asiduamente en las estancias del señor cardenal. Este abrió las puertas y fue a palacio para solicitar que fuesemos recibidos, lo que ocurrió poco después". El arquitecto les acompaña en la visita a El Escorial y en el detallado recorrido que hacen el 14 de julio por el convento de la Encarnación. Y también es Mora quien acude por el jardín de la Priora, a la una de la madrugada del día 29 de julio a despertar a monseñor Pamphili para que avise al legado que la marquesa de Heliche -la hija de Olivares- se muere, y acuda a sus aposentos a darle la extremaunción ${ }^{18}$.

\footnotetext{
${ }^{15}$ Simón Díaz, J. (ed), 1982: 349; 1980: 175.

${ }^{16}$ Certificación de Gómez de Mora del 31 de marzo de 1626. La liquidación de estas vidrieras no llegó hasta el 31 de mayo de 1638, autorizada entonces por Carbonel. De colocarlas se ocupó el vidriero real Diego del Campo que suministró también cinco faroles para alumbrar el acceso y los patios. AGP. Caja 9.390 expte. 5, y AGP. SA. Leg. 710.

${ }^{17}$ Biblioteca Apostólica Vaticana, Cod. Barberini Lat. 3272. Gómez DE MorA, J., 1986: 379-397.

${ }^{18}$ Anselmi, A. 2004.
} 
Viendo al maestro mayor pavonearse entre los invitados del monarca, no sabe uno si ya está barruntando los negros nubarrones que se ciernen sobre su futuro, y que acabarán por arruinar su carrera en palacio. Pero dejemos que las cosas pasen a su tiempo y volvamos a los pagos realizados con motivo de la visita del cardenal. Una de las libranzas, fechada el 18 de mayo de 1626, dice: "Se compraron de Antonio Mancheli estanpero veçino de Madrid dos mapas hunibersales que dio para la Casa del Tesoro donde se a de aposentar el legado de Su Santidad a rraçon de a nobenta reales cada una = y otra mapa de España en treynta y tres reales y otra mapa de Aragon en treynta y tres reales y un arboro de las armas y titulos de los Reyes de Ynglaterra en treynta y tres reales $=$ y doçe mapas medianas en nobenta y seis reales que todo monta trecientos y setenta y cinco reales como parece por el concierto que con el susodicho hiço el maestro mayor Juan Gomez de Mora" 19 .

Fue Matilla Tascón quien relacionó el nombre de Antonio Mancelli con el primer plano conocido de la Villa -el popularizado por la estampa de De Wit-, al publicar los documentos del contrato, fechado en septiembre de 1622, por el que recibía el encargo del ayuntamiento. Poco después el mismo investigador sacaba a la luz las disposiciones testamentarias de Mancelli con lo que empezaba a tomar cuerpo un personaje cuyo nombre había pasado hasta entonces un tanto desapercibido para los estudiosos del pasado madrileño ${ }^{20}$. La aparición de otro plano suyo, en este caso de la ciudad de Valencia, fechado en 1609, aportaba en su leyenda nuevos datos sobre los hasta entonces cono$\operatorname{cidos}^{21}$. A partir de ahí, y tras una rigurosa revisión de los Libros de Acuerdos del Archivo de la Villa y los originales del de Protocolos, Muñoz de la Nava Chacón pudo ya hilvanar el bosquejo de una biografía ${ }^{22}$. Resumiendo toda esta información hoy sabemos que Mancelli, aunque se declare romano, procedía de una familia originaria de Módena. Debió llegar a Valencia a principio de siglo y allí buscó la protección del virrey don Luis Carrillo, marqués de Taracena, al que dedicó en 1608 el plano de la ciudad. El marqués fue nombrado en 1615 presidente del consejo de Órdenes con asiento en los de Estado y Guerra y es posible que Mancelli se trasladara junto a él a Madrid. En cualquier caso, cuando el 20 de agosto de 1622 ofrece al Ayuntamiento la estampación de un plano de la Villa, dice llevar ya ocho años trabajando, "con mucha puntualidad y costa por sacar un mapa desta Real Corte", mapa de cuya calidad Mancelli está tan seguro como para ofrecer al ayuntamiento que sea revisado ni más ni menos que por Gómez de Mora, Gil González Dávila y Juan Bautista de Labaña ${ }^{23}$. Aunque en principio se identificó directamente el plano de Mancelli con la imagen grabada por Frederik de Wit, esta cuestión ha sido después, y continua siendo, objeto de debate ${ }^{24}$.

Molina Campuzano, antes de que el plano se vinculara a Mancelli y reconociendo la dificultad de poder fijar su fecha, propuso situarlo en torno a 1635, atendiendo a la presencia de algunos edificios como el Colegio Imperial, que aparecen ya representados y que a principios de los años veinte, apenas estarían saliendo de sus cimientos ${ }^{25}$. En contra de esta opinión se ha argumentado que el autor podría haber hecho los dibujos porque tuviera información directa de los proyectos que se iban a construir, cosa que no deja de ser posible ${ }^{26}$. Y una mirada atenta al plano que, para

\footnotetext{
${ }^{19}$ AGP. SA. Leg. 5.208.

${ }^{20}$ Matilla Tascón, A., 1980: 103-107; 1982: 199-202.

${ }^{21}$ Benito Domenech, F., 1992: 29-37; 1994: 231-245.

${ }^{22}$ Muñoz de la Nava Chacón, J.M., 2005: 45-79; 2006: 165-219.

${ }^{23}$ Según el ofrecimiento hecho a la Villa el 20 de agosto de ese año publicado por Pérez Pastor, C., 1891-1907, T. III: $158-160$.

${ }^{24}$ Retrasa la fecha del plano De Wit, y por lo tanto lo distancia del de Mancelli, PeredA, F., 1998: 103-134 y en cambio mantiene la identificación entre uno y otro MuÑoz de LA NAVA Chacón, J.M., 2005: 45-79; 2006: 165-219.

${ }^{25}$ Molina Campuzano, M., 1960: 220-230.

${ }^{26}$ Por ejemplo en el caso de la iglesia de los Jesuitas, aunque la primera piedra del nuevo edificio no se puso hasta el 5 de abril de 1622, un cronista como León Soto, ya sabía entonces que la iglesia iba a ser "cosa grandiosa, según la traza que se ha de ejecutar”. León Soto, A., Noticias de Madrid, Biblioteca Nacional Mss. 2395.
} 
facilidad de nuestra exposición y sin querer entrar en la polémica sobre su autoría, vamos a llamar Mancelli-De Wit, deja ver como a pesar de que la ciudad se encontraba entonces en plena ebullición constructiva, ninguno de sus edificios se dibuja en obras, sorprendente decisión, muy distinta de la que tomará después Texeira. Pero mucha de la susceptibilidad hacia lo representado en el plano venía de la aparente falta de precisión con la que parecían tratados algunos de los conjuntos monumentales más importantes y mejor conocidos de la ciudad, como el palacio real y la Plaza Mayor. En cuanto al alcázar, la que se tenía por fantasiosa imagen, con dos aparatosas torres flanqueando su pórtico central, sabemos hoy que podría guardar cierta correspondencia con lo proyectado por Gómez de Mora en 1612, cuando varió el proyecto de su tío Francisco de Mora, decidiendo incorporar las dos antiguas torres medievales al frente de la fachada. Antes de que se interrumpieran las obras, una de ellas llegó a levantarse, colocándose encima una grúa para subir la madera con la que armar su chapitel, aunque la madera nunca llegó, y después de unos años, en 1629, un auto del ayuntamiento ordenó desmontarla y llevar a cabo una cubierta provisional ${ }^{27}$ (fig. 3).

Aunque el dibujo sea de tan poca calidad, la vista de los Anales de Khevenhüller, con la llegada del príncipe de Gales al alcázar en 1623, tiene el valor de ser el único testimonio que hasta ahora conocemos de aquel momento de la vida del edificio. Esa vista y la credibilidad que demos al

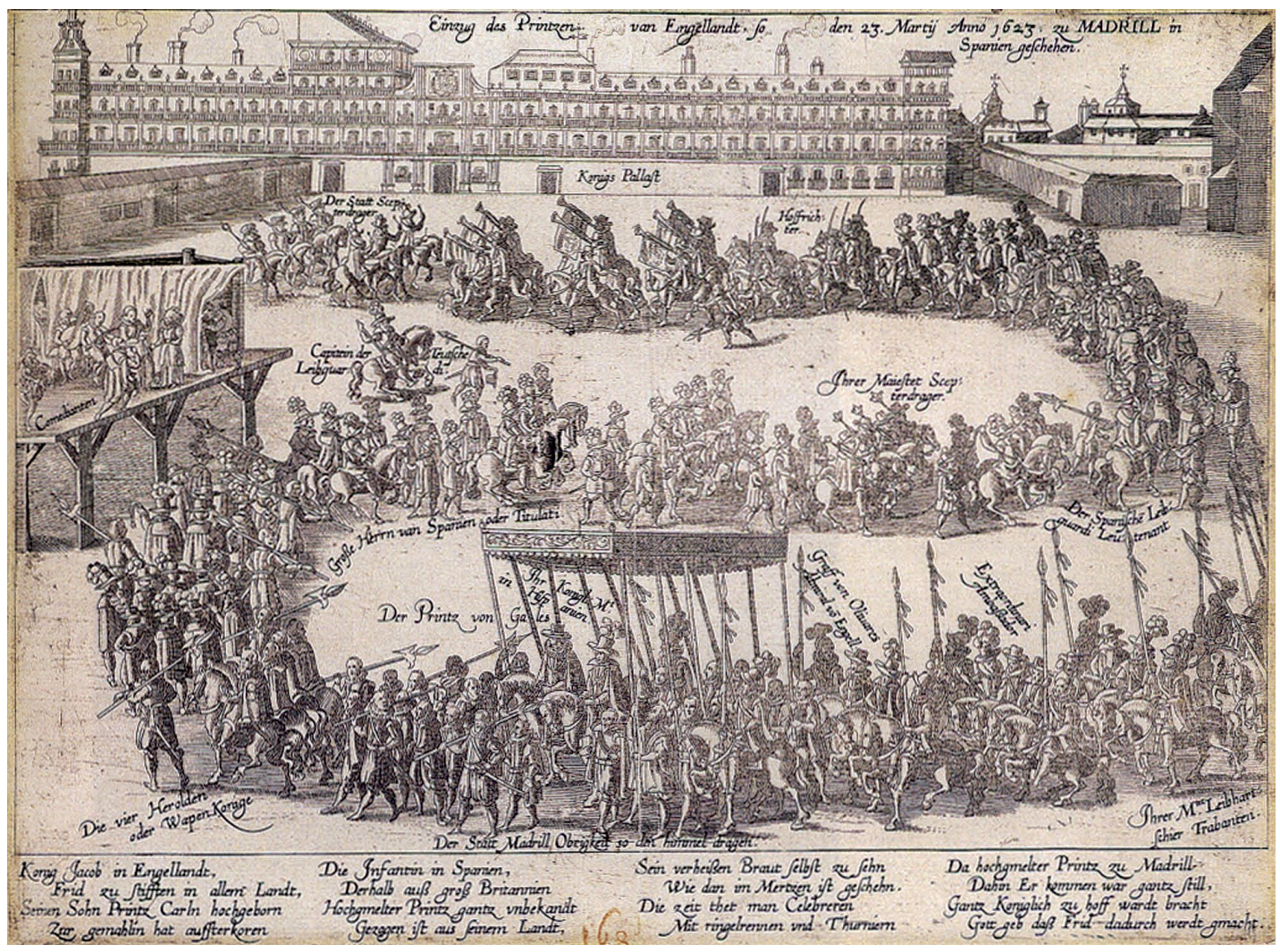

Fig. 3. Anales de Khevenhüller, La llegada al alcázar del Príncipe de Gales en 1623.

\footnotetext{
${ }^{27}$ De la que se conserva un croquis en el Archivo de la Villa, ASA 1-161-31.
} 
plano Mancelli-De Wit donde se representan las dos torres centrales de la fachada coronadas con sus chapiteles de remate. Por tanto, y con todas las prevenciones que al respecto quieran hacerse, se trata de una imagen que obligadamente debe considerarse en cualquier hipotética reconstrucción del proyecto original del maestro mayor ${ }^{28}$ (fig. 4).

De todas formas tampoco parece muy razonable pensar que el autor del plano se inventara por su cuenta un detalle como ese, -dar tantas alas a la fantasía de Mancelli, si fue él quien lo hizoy menos en un edificio tan singular como era el palacio del rey. Sobre todo porque el plano muestra precisión en otros aspectos del conjunto. Molina Campuzano puso su atención en el monumental paredón del Parque proyectado en 1625 por Gómez de Mora, tres de cuyos cubos, los únicos que se construyeron, pueden verse representados en el plano de Texeira, donde a veces llegaron a ser confundidos con restos de la muralla ${ }^{29}$. En una planta del paredón, conservada en el Archivo de la Villa, aparece también dibujado un primer muro, o más propiamente pretil, que ajustándose a la topografía, discurría paralelo a la fachada oeste del alcázar, quebraba su perfil para adelantarse formando una especie de ensanche o mirador, y luego buscaba en diagonal la esquina del jardín del Rey. No sabemos cuando se construyó ese primer paredón, pero entre 1618 y 1619 se registran numerosos pagos para el jardín del Rey o de los Emperadores cuya geometría se regulariza entonces, y entre ellos hay varios que se refieren al "paredon del jardin del rey, o al palenque del ensanche del camino para bajar al Parque", más específicamente "para que el rey pudiera tomar el coche cuando bajaba al Parque", y puede ser que alguna de estas libranzas tuvieran que ver con dicha obra $^{30}$. En cualquier caso, se construyera cuando se construyera, ese primer paredón, que ya no está en el plano de Texeira, sí aparece correctamente dibujado en el plano de Mancelli-De Wit. Es un detalle, pero muestra que su autor conocía, y era capaz de dibujar con cierta precisión, el entorno

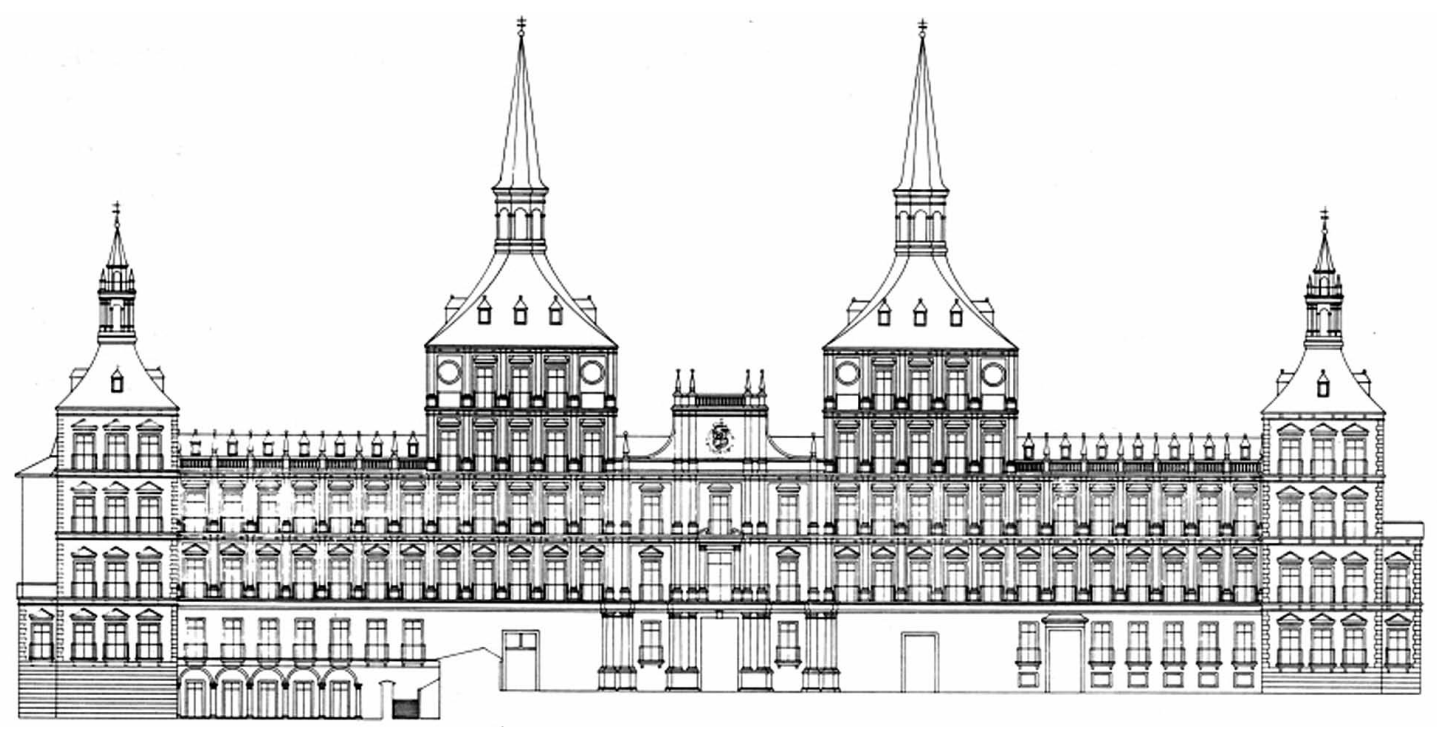

Fig. 4. J.M. Barbeito, Restitución del proyecto de Gómez de Mora para la fachada del alcázar.

\footnotetext{
${ }^{28}$ Barbeito, J.M., 1992.

${ }^{29}$ Molina Campuzano, M., 1975: 193-205.

${ }^{30}$ AGP. SA. Leg. 710.
} 
de palacio. En definitiva, creo que en 1622 Juan Gómez de Mora, por lo que respecta al alcázar, no habría tenido mucho que objetar a lo representado en el plano (fig. 5).

Más complicado es entender lo de la Plaza Mayor. Si hay algo que permite su inmediata identificación en el abigarrado caserío de la trama urbana, es la rotundidad de su geometría. Sin embargo en el plano Mancelli-De Wit solo aparecen escuadrados el flanco oriental y el de mediodía - donde se dibuja la casa de la Panadería-, mientras que en el lado de poniente, el que daba hacía las cavas, la geometría se descompone dejando el plano un gran vacío a la izquierda de la embocadura de la calle de Toledo, que irregulariza el espacio. Esta representación de la plaza resultaría completamente inaceptable en 1622 (fig. 6). Inaceptable para el Ayuntamiento que encargaba el plano e inaceptable para Mancelli, cosa que podemos asegurar después de que apareciera un ejemplar de su otra estampa, la que se puso a la venta con el plano, donde la plaza figura ya perfectamente escuadrada $^{31}$. Lo único que cabe pensar es que la estampa viniera a subsanar esa clamorosa inexactitud del plano, complementando su información, pero no se entienden las razones para no corregirlo antes de estamparlo, y en cualquier caso, de haber sido así, como la documentación no se hace eco de todo ello. Parece después de eso difícil seguir sosteniendo la identificación entre el que hemos llamado plano Mancelli-De Wit y el presentado en 1622 al Ayuntamiento.

En este punto convendría precisar algo los tiempos. Muñoz de la Nava Chacón recoge un acuerdo del 11 de octubre de 1621 para pagar al grabador Juan Escotens -quizás Jan Schorkens-, "una pintura de esta villa en el estado en que hoy está", y apunta, con reservas, que podría tratarse de la apertura de las planchas para el plano de Mancelli, lo que adelantaría todavía un poco más la fecha de los dibujos definitivos ${ }^{32}$. Si de otra parte miramos las obras de la plaza, podemos recordar

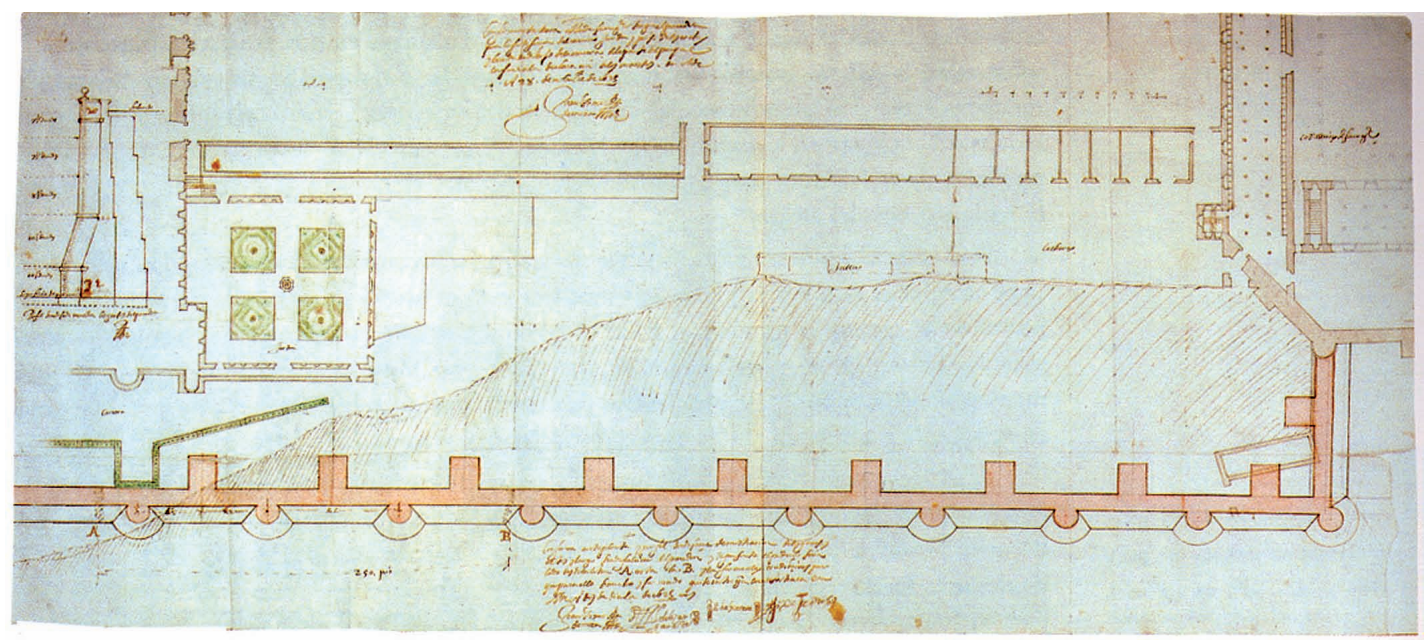

Fig. 5. Juan Gómez de Mora, Proyecto para el Paredón del Parque, 1625. AV. ASA. 1-161-17.

${ }^{31}$ Escobar, J. R., 2005; 2003. Todavía falta, sin embargo, una restitución planimétrica rigurosa que nos permita entender la evolución del espacio urbano, desde que en 1583 empezaran las primeras obras de demolición de las "casas de la mançana".

${ }^{32}$ Muñoz de la Nava Chacón, J.M., 2005: 65. Hace bien el autor en manifestar su cautela a la hora de relacionar el acuerdo de la Villa con el trabajo de Mancelli. Se habla de láminas de bronce en vez de planchas de cobre y se considera un coste "muy acomodado" el de 500 ducados, esto es 5.500 reales. Téngase en cuenta que ese mismo año se habían pagado a Pedro Perret, grabador del rey, 600 reales por abrir las tres planchas del túmulo de Felipe III en San Gerónimo, a razón de 200 reales cada una. AGP. SA. Leg. 5.208, libranza de 29 de mayo de 1621. 


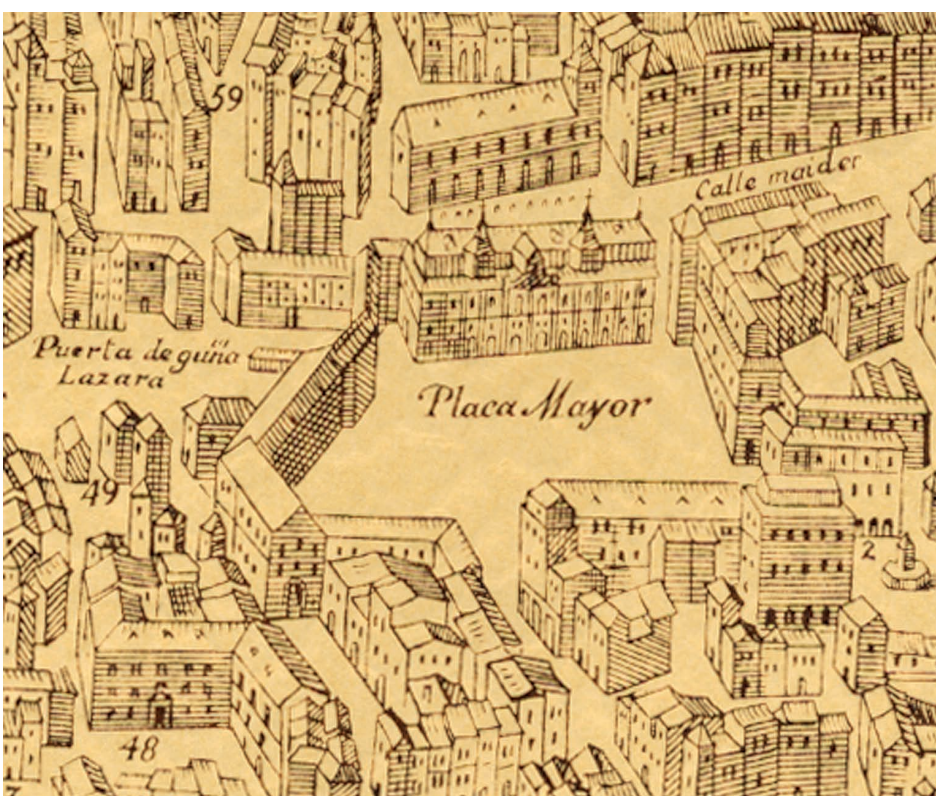

Fig. 6. Fragmento del plano La Villa de Madrid corte de los Reyes Catolicos de Espanna.

como terminadas las primeras demoliciones se cerró el espacio con tablones, para correr, el 4 de diciembre de 1617 , toros y cañas delante del rey y de los príncipes. El ensayo puso en evidencia la estrechez del sitio, tomándose entonces la decisión de ensancharlo y proceder a nuevos derribos ${ }^{33}$. Más se tardó en decidir el trazado de la calle Nueva, acceso principal a la plaza desde la Puerta de Guadalajara, calle que terminó construyéndose derecha y alineada, sin quiebros ni rincones, tal como quedó dibujada en un plano de Gómez de Mora fechado el primero de julio de 1620. Pero todavía a comienzos de ese año el maestro mayor solicitaba demoler algunas casas, para cerrar aquel rincón de la plaza en correspondencia con los otros tres, llegando el enfrentamiento sobre su trazado a tal extremo, que Gómez de Mora se vio durante unos días arrestado en su casa, acusado de alterar las alineaciones en provecho de algunos de los vecinos. Es interesante que la documentación recoja la existencia de unos modelos con los que Gómez de Mora debió explicar las distintas opciones a los regidores de la Villa, por lo que estos modelos hubieran podido servir para facilitar el trabajo del corógrafo ${ }^{34}$ (fig. 7).

En definitiva, dado que Mancelli era perfectamente capaz de dibujar la plaza en 1622 -y además desde un punto de vista prácticamente coincidente con el que tenía en el plano-, si queremos seguir relacionando este con Mancelli, hay que buscar otra explicación a lo que allí vemos. Una sería pensar en una copia tardía y descuidada, que hubiera perdido por el camino la regularidad del trazado de la plaza ${ }^{35}$. Quizás porque se entendiera lo representado como una imagen más simbólica que científica de la ciudad, en la que no importara demasiado la verosimilitud de los detalles. Lo importante sería entonces el significado de la imagen en su conjunto y eso justificaría la idea de urbe acabada, sin obras aparentes, que antes señalábamos ${ }^{36}$. Pero también cabe otra posibilidad, y es que el plano grabado por de Wit a mediados de siglo, se hubiera levantado, no sobre el plano editado por Mancelli, sino sobre un dibujo preparatorio de los muchos que debió hacer en los ocho años que trabajó sobre el plano, y que tendríamos que fechar entre 1619 y 1620 . Estado previo,

\footnotetext{
${ }^{33}$ Hay numerosas referencias sobre ello. Gascón de Torquemada lo resume así: A los 4 (de diciembre de 1617) huvo toros y cañas en la Plaça Mayor de Madrid, para que el Rey viese la forma en que después de hechos los tablados quedava la Plaça, y pareció pequeña, y asi se derribaron más casas. GASCón DE TORQUEMADA, J., 1991: 45.

${ }^{34}$ Lapuerta Montoya, M. de, 1994: 73-87 y Escobar, J. R., 2003.

${ }^{35}$ Lo mismo que perdió las imágenes con las que el Ayuntamiento quiso se orlaran las márgenes del plano y que han sido pormenorizadamente estudiadas en MuÑoz de LA NAVA Chacón, J.M., 2006.

${ }^{36}$ Pereda, F., 1998.
} 


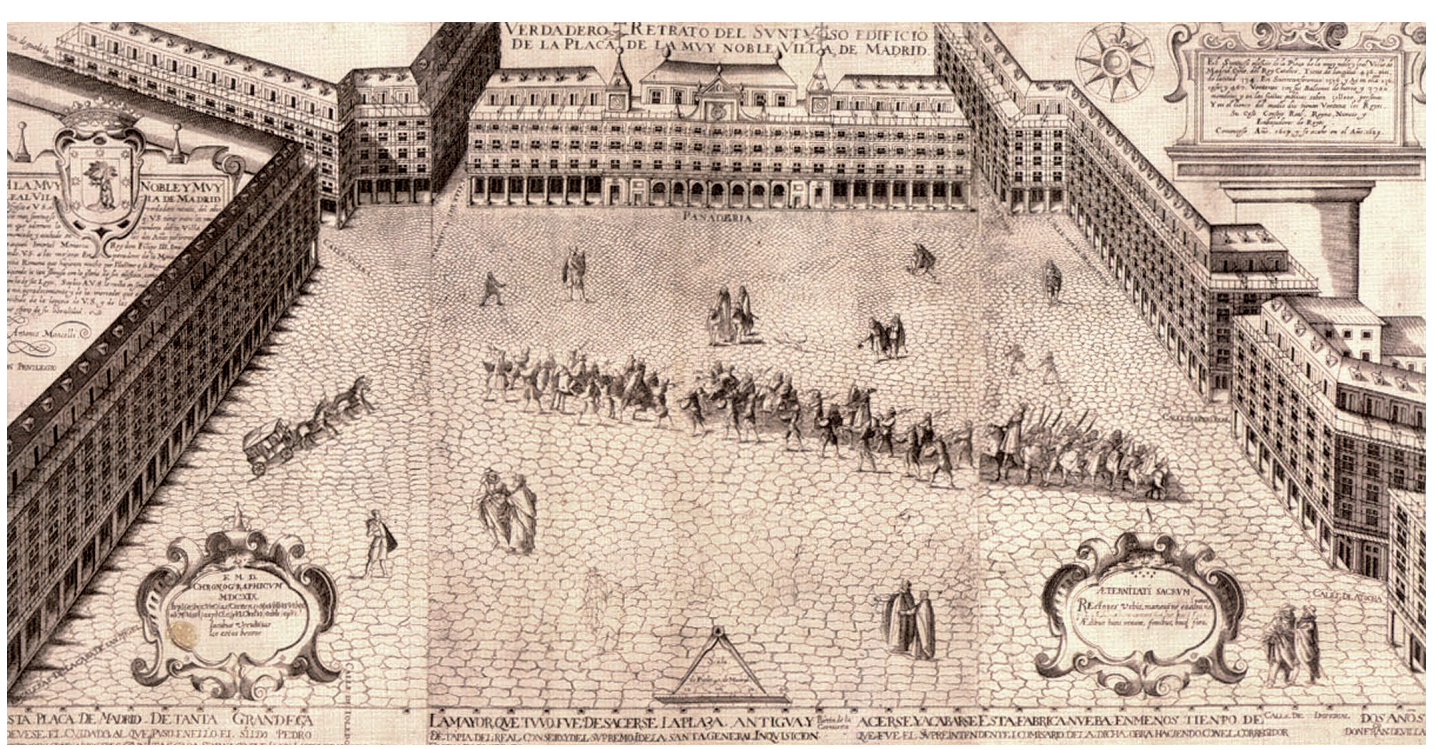

Fig. 7. Antonio Mancelli, Verdadero retrato del suntuoso Edificio de la Plaça de la muy noble villa de Madrid. British Library, Londres.

en el que si bien la imagen del alcázar podía ya precisarse, todavía no se conocía cual iba a ser la solución final para el flanco oeste de la plaza Mayor, ni como iba a cometer en ella la calle nueva que se abría desde la puerta de Guadalajara.

En cualquier caso la nota del Archivo de Palacio refuerza la idea de una relación directa entre Gómez de Mora y Mancelli. Es probable que Mancelli a su llegada a Madrid se aproximara al influyente grupo de artistas italianos que trabajaban en la corte. La primera noticia suya conocida tenía que ver con ellos: a la muerte de Cajés, las planchas que ilustraban su traducción de la Regola de Vignola, pasaron a Carducho quien sacó una segunda edición, a la que en 1619 se añadió en el frontispicio "Se vende en casa de Antonio Mancelli". Gómez de Mora mantenía una estrecha relación con estos pintores, sucesores a la postre de los que junto a su padre trabajaron en El Escorial, y Carducho será uno de los últimos en defender en 1633 al maestro mayor, poco antes de que fuera condenado y apartado de su oficio, cuando en sus Dialogos de la Pintura, haga un encendido elogio de las obras que había dirigido en el alcázar ${ }^{37}$.

De otra parte Pérez Pastor daba la noticia de que en 1623 un Manceli, al que aún no se relacionaba con el plano de Madrid, había instalado su tienda de libros y estampas en uno de los patios del alcázar, "un cajón grande y un cajoncillo pequeño que está al lado de la escalera". Pagó por el traspaso al librero Antonio Rodríguez 50 ducados y seis ejemplares del Vignola ${ }^{38}$. Hoy nos puede parecer sorprendente que los patios de palacio estuvieran ocupados por una multitud de tenderetes -cajones, como los llama la documentación-donde se vendían todo tipo de artículos, especialmente aquellos que podríamos considerar manufacturas de lujo, como telas, pasamanerías, libros, etc. Pero sucedía así, y estas "tiendas" al parecer estaban a cargo del maestro mayor, pues en un papel de 1611, la Junta de Obras y Bosques pregunta a Gómez de Mora "con que titulo tenia Francisco

\footnotetext{
${ }^{37}$ Carducho, V., 1633.

${ }^{38}$ Pérez Pastor, C., 1891-1907, y Muñoz de la Nava Chacón, J.M., 2006: 168-169.
} 
de Mora las tiendas de los bohoneros de palacio questan en los patios del, y quien los tiene oy y con que orden, o como esta esto" ${ }^{39}$. La relación de Mancelli, - un italiano que vendía libros de Vignola en el patio del alcázar- con el maestro mayor, puede darse por segura. Desde cuando se arrastraba esta relación es más difícil de establecer, pero es probable que ya mientras preparaba su plano, Mancelli pudiera contar con una información directa por parte de Mora.

Hay que suponer el placer con el que los ojos de Cassiano, el ávido coleccionista del Museum Carthaceum, recorrerían las paredes de ese pequeño pasadizo, tras la capilla, donde colgaban las estampas suministradas por Mancelli. La relación de Gómez de Mora cita dos mapas universales, los más costosos, valorados cada uno de ellos en 90 rs., y los de España y Aragón, junto a la genealogía de los reyes ingleses, pagados a 33 rs. Luego, los 12 mapas medianos, valorados en conjunto en 96 reales, esto es, a 8 rs. el mapa. Exactamente el mismo precio que Mancelli había pedido al Ayuntamiento si se necesitaban mas ejemplares del plano de Madrid o de la vista de la Plaza Mayor, después de las primeras 300 estampas comprometidas en 1622. ¿Se encontrarían ejemplares de uno y otro entre estos "mapas medianos" colgados en el pasadizo? ¡Qué sugerente sería imaginar a Barberini reconociendo cada día en el plano de la Villa los palacios y conventos que iba a visitar! ${ }^{40}$.

Si el plano de Mancelli se ha querido identificar con el grabado por De Wit, la vista de la plaza se daba por perdida, hasta que apareció el ejemplar conservado en la British Library, dedicada a la Villa de Madrid y firmada por Antonio Mancelli. Cuando la dio a conocer, Jesús Escobar anotaba como esos fondos provenían de la colección del rey Jorge III con lo que, en opinión de los conservadores, la vista podría formar parte de la compra realizada en 1762 al Cardenal Albani, en la que se encontraban los papeles del Museum de Cassiano dal Pozzo ${ }^{41}$. Se establecía así un hilo de conexión entre el coleccionista italiano y la vista de Mancelli, reforzada por el hecho de haberse encontrado en Widsor Castle otros dos dibujos de la Plaza Mayor, una planta y el alzado sur, dibujos también provenientes de su colección ${ }^{42}$. La libranza de Gómez de Mora en el Archivo de Palacio es otro eslabón más con el que atar la relación entre ambos personajes.

\section{BIBLIOGRAFÍA}

Anselmi, Alessandra, El diario del viaje a España del cardenal Francesco Barberini escrito por Cassiano dal Pozzo, Madrid 2004.

Barbeito, José Manuel, El Alcázar de Madrid, Madrid 1992.

Barbeito, José Manuel, “Olivares en palacio”, Libros de la Corte, n², Madrid 2010, pp. 65-71.

\footnotetext{
${ }^{39}$ AGP. Junta de Obras y Bosques, Libro 1, reg. 23

${ }^{40}$ El 6 de agosto, unos pocos días antes de que partiera el cardenal, le llevaron de parte del rey un cuadro con el Juego de Cañas celebrado en 1623 en la Plaza Mayor, cuando estaba en la ciudad el Príncipe de Gales. Hasta nosotros ha llegado el de Juan de la Corte que recoge el mismo festejo. Cassiano dice como Gómez de Mora, que acompañó a los que llevaban el cuadro, aprovechó para dar una detallada descripción de aquella fiesta, no sabemos si solo de palabra o también por escrito. AnSELmi, A. 2004: 298.

${ }^{41}$ Escobar, J.R., 2005. Puede que el cardenal Barberini decidiera llevarse parte o todos los planos comprados a Mancelli, con lo que tal vez una búsqueda en la Biblioteca Vaticana permitiera su identificación. Parece que tanto el plano como la vista de la plaza llegaron a otras colecciones italianas, como la de los Colonna, según apunta MuÑoz DE LA NAVA Chнсо́n, J.M., 2006: 172 n. 96, y 180 n. 121. Girolamo Colonna, que residía entonces en Madrid, fue hasta Guadalajara para recibir el 8 de mayo de 1626 al cardenal Barberini, acompañándole hasta que hizo su entrada en la Villa. Estuvo muy activo durante toda la visita, lo que no dejaría de considerarse para su propia promoción dos años después al capelo cardenalicio. Anselmi, A., 2004.

${ }^{42}$ Marías, F., y Bustamante, A., 1991: 74-85.
} 
Benito Domenech, Fernando, “Un plano axonométrico de Valencia diseñado por Manceli en 1608”, en Ars Longa. Cuadernos de Arte, $\mathrm{n}^{\circ}$ 3, 1992, pp. 29-37.

Benito Domenech, Fernando, "El plano de Valencia de Mancelli" en Tiempo y espacio en el Arte. Homenaje al profesor Antonio Bonet Correa, Madrid 1994, pp. 231-245.

Cabrera de Córdoba, Luis, Relaciones de las cosas sucedidas en la corte de España 1599-1614, Madrid 1857.

Carducho, Vicente, Diálogos de la Pintura, Madrid 1633, ed. a cargo de Calvo Serraller, Francisco, Madrid 1979.

Escobar, Jesús, The Plaza Mayor and the Shaping of Baroque Madrid, Cambridge, Cambridge University Press, 2003, versión española La Plaza Mayor y los orígenes del Madrid Barroco, San Sebastián 2007.

Escobar, Jesús, "Antonio Manzelli. An early View of Madrid (c. 1623) in the British Library", Anuario del Departamento de Teoría e Historia del Arte, UAM, vol. XVII, 2005, pp. 33-38.

García Mercadal, José, Viajes de extranjeros por España y Portugal, Madrid 1952-1962, reed. Junta de Castilla y León 1999.

Gascón de Torquemada, Jerónimo, Gaçeta y nuevas de la corte de España, ed. a cargo de Ceballos-Escalera y Gila, Alfoso, Madrid 1991.

Gerard, Veronique, "La fachada del Alcázar de Madrid", Cuadernos de Investigación Histórica, n 2, 1978, pp. 327-257.

Gómez de Mora, Juan, "Relaçion de las Cassas que tiene el Rey en España" en Tovar, Virginia (comisaria), Juan Gómez de Mora (1586-1648), cat. exp., Madrid, Ayuntamiento de Madrid, 1986, pp. 379-397 (transcripción de Mercedes Agulló).

Lapuerta Montoya, Magdalena de, "Conflictos en la reforma de la "calle nueva que ba de la puerta de Guadalaxara a la Plaça": datos sobre la prisión de su autor, Juan Gómez de Mora", en Madrid en el contexto de lo hispánico desde la época de los descubrimientos, t. I, Madrid 1994, pp. 73-87.

Marías, Fernando, y Bustamante, Agustín, "De las Descalzas Reales a la Plaza Mayor: Dibujos madrileños en Windsor Castle de la colección de Cassiano dal Pozzo", Cinco siglos de Arte en Madrid, Madrid 1991, pp. 74-85.

Martínez Díaz, Ángel, Espacio, Tiempo y Proyecto. El entorno urbano del Palacio Real de Madrid entre 1735 y 1885 , Madrid 2008.

Matilla Tascón, Antonio, "Autor y fecha del plano más antiguo de Madrid. La incógnita resuelta" en Anales del Instituto de Estudios Madrileños, vol. XVII, 1980, pp. 103-107.

Matilla Tascón, Antonio, "En torno al autor del primer mapa de Madrid. El testamento de Antonio Manceli" en Anales del Instituto de Estudios Madrileños, vol. XIX, 1982, pp. 199.

Molina Campuzano, Miguel, Planos de Madrid de los siglos XVII y XVIII, Madrid 1960.

Molina Campuzano, Miguel, "Explicación de un detalle del plano de Madrid por Texeira: el muro de contención o paredón del Parque ante la fachada oeste del alcázar, proyectado por Gómez de Mora en 1625", Homenaje a don Agustín Millares Carlo, T. II, Madrid 1975, pp. 193-205.

Muñoz de la Nava Chacón, José Miguel, "Antonio Mancelli: un corógrafo, iluminador, pintor y mercader de libros en el Madrid de Cervantes (I)", Torre de los Lujanes, no 57, 2005, pp. 45-79.

Muñoz de la Nava Chacón, José Miguel, "Antonio Mancelli: un corógrafo, iluminador, pintor y mercader de libros en el Madrid de Cervantes (II)", Torre de los Lujanes, n 58, 2006, pp. 165-219.

Pereda, Felipe, "Iconografía de una capital barroca. Madrid entre el simbolismo y la ciencia", Espacio, Tiempo y Forma, serie VII, $\mathrm{H}^{\mathrm{a}}$ del Arte, t.11, 1998, pp. 103-134.

Pérez Pastor, Cristóbal, Bibliografia Madrileña de los siglos XVI y XVII, Madrid 1891-1907.

Porreño, Baltasar, Dichos y Hechos del señor Rey don Felipe Segundo el Prudente ... Sevilla 1639.

Quintana, José, A la muy antigua, noble y coronada Villa de Madrid. Historia de su antigüedad, nobleza y grandeza, Madrid 1629.

Simón Díaz, José. (ed.), Relación de actos públicos celebrados en Madrid (1541-1650), Madrid 1982.

Simón Díaz, José, "La estancia del Cardenal Legado Francesco Barberini en Madrid el año 1626", Anales del Instituto de Estudios Madrileños, T. XVII (1980) pp. 159-213.

Tovar, Virginia, "Juan Gómez de Mora. Arquitecto y Trazador del Rey y Maestro Mayor de Obras de la Villa de Madrid”, en cat. exp. Juan Gómez de Mora (1586-1648), Madrid 1986.

Fecha de recepción: 5-X-2011

Fecha de aceptación: 29-XII-2011

Arch. esp. arte, LXXXVI, 342, ABRIL-JUNIO 2013, 107-122, ISSN: 0004-0428 